УДК 343.3

\title{
С.А. Стяжкина
}

\section{УГОЛОВНО-ПРАВОВАЯ ОХРАНА ЧАСТНОЙ ЖИЗНИ ЛИЦА}

В статье рассматриваются вопросы квалификации преступления, предусмотренного ст. 137 УК РФ «Нарушение неприкосновенности частной жизни лица». Особое внимание уделено проблеме определения понятий «частная жизнь лица», «личная тайна», «семейная тайна» как предметам уголовно-правовой охраны. Анализируются объективные и субъективные признаки состава нарушения неприкосновенности частной жизни лиц, а также вопросы исключения отдельных лиц из числа субъектов по данному составу преступления. Автор предлагает внести изменения в ст. 137 УК РФ, касающиеся предмета преступления и отнесения ряда признаков объективной стороны к числу квалифицированных. Достаточно подробно анализируются признаки преступления, предусмотренного ч. 3 ст. 137 УК РФ: ответственность за незаконное распространение в публичном выступлении, публично демонстрирующемся произведении, средствах массовой информации или информационнотелекоммуникационных сетях информации, указывающей на личность несовершеннолетнего потерпевшего, не достигшего шестнадцатилетнего возраста, по уголовному делу либо информации, содержащей описание полученных им в связи с преступлением физических или нравственных страданий, повлекшее причинение вреда здоровью несовершеннолетнего, или психическое расстройство несовершеннолетнего, или иные тяжкие последствия.

Ключевые слова: частная жизнь лица, личная тайна, семейная тайна, распространение сведений, собирание сведений, публичность.

DOI: $10.35634 / 2412-9593-2019-29-4-538-544$

В соответствии с Конституций РФ «каждый имеет право на неприкосновенность частной жизни, личную и семейную тайну, защиту своей чести и доброго имени» (ст. 23 Конституции РФ), «сбор, хранение, использование и распространение информации о частной жизни лица без его согласия не допускаются» (ст. 24 Конституции РФ) ${ }^{1}$. Таким образом, Конституция РФ гарантирует каждому неприкосновенность его частной жизни, личной и семейной тайны.

Уголовный кодекс РФ предусматривает ответственность за нарушение неприкосновенности частной жизни лица, которое выражается в незаконном собирании или распространении сведений о частной жизни лица, составляющих его личную или семейную тайну, без его согласия либо распространение этих сведений в публичном выступлении, публично демонстрирующемся произведении или в средствах массовой информации ${ }^{2}$.

Следует отметить, что за последние годы количество преступлений, предусмотренных ст. 137 УК РФ, неуклонно растет. По данным Судебного департамента при Верховном Суде РФ, за последние 5 лет количество осужденных по ст.137 УК выросло в 4 раза (с 31 человека в 2014 г. до 127 в 2018 г.). Связано это, прежде всего, с развитием информационно-телекоммуникационных сетей и проблемами защиты информации, размещенной на электронных носителях. Все большую актуальность приобретают вопросы уголовно-правовой защиты информации о частной жизни лица, представленной в виде компьютерной информации.

Практика применения ст. 137 Уголовного кодекса РФ свидетельствует о том, что не всегда однозначно судами оцениваются такие понятия, как «личная тайна», «семейная тайна», «частная жизнь лица». Кроме того, остаются нерешенными вопросы правил квалификации состава нарушения неприкосновенности частной жизни лица, сведения о которой представлены в виде электронных сигналов.

Прежде всего, необходимо остановиться на вопросе определения объекта рассматриваемого состава преступления. Родовым объектом нарушения неприкосновенности частной жизни лица будут выступать отношения, обеспечивающие безопасность личности. Личность как носитель и обладатель различных прав и обязанностей, как субъект и объект различного рода отношений, в том числе и правовых, поставлена под защиту государства. Первостепенное значение уделяется именно вопросам охраны личности, ее прав, законных интересов.

\footnotetext{
${ }^{1}$ Конституция Российской Федерации (принята всенародным голосованием 12.12.1993 г.) // СПС «Гарант».

${ }^{2}$ Уголовный кодекс РФ 1996 г.// СПС «Гарант».
} 
Видовым объектом данного преступления выступают отношения, обеспечивающие защиту конституционных прав и свобод личности.

Непосредственным объектом преступления, предусмотренного ст. 137 УК РФ, будут выступать общественные отношения, обеспечивающие неприкосновенность частной жизни лица. Речь идет о конституционном праве на неприкосновенность частной жизни лица, его личной и семейной тайны.

Особую актуальность проблема защиты этого права приобретает в современном обществе, носящем информационный характер. Следует отметить, что лица зачастую сами выкладывают сведения о своей жизни в СМИ, информационно-телекоммуникационных сетях, предоставляя к ним доступ многим лицам. Не все еще умеют грамотно использовать информационные ресурсы, с одной стороны, предоставляющие огромные возможности для общения и работы, но, с другой - содержащие угрозы незаконного вмешательства в различные сферы жизни людей, связанные с размещением информации в сети Интернет.

С вопросом объекта тесно связано проблема определения предмета данного преступления, в качестве которого выступают сведения о частной жизни лица, составляющие его личную или семейную тайну. Исходя из нормы уголовного закона можно сделать вывод, что предметом преступления являются не любые сведения о частной жизни лица, а только такие сведения, которые составляют личную или семейную тайну. Отсюда следует, что личная или семейная тайна выступает в качестве составляющей частной жизни лица. Хотя Конституция РФ не отождествляет эти понятия, а рассматривает их в качестве равноценных, перечисляя их в ст. 23, гарантирующей всем неприкосновенность частной жизни лица, его личной, семейной тайны.

Если обратиться к понятию частной жизни лица, то следует отметить, что в литературе существует огромное количество определений частной жизни лица, к которым относят, в частности, сведения о состоянии здоровья, сексуальной ориентации, о политических, религиозных взглядах и убеждениях, о имущественном положении, о взаимоотношениях в семье, с друзьями и т.д. Одно из определений частной жизни лица было дано Конституционным Судом РФ: «в понятие “частная жизнь" включается та область жизнедеятельности человека, которая относится к отдельному лицу, касается только его и не подлежит контролю со стороны общества и государства, если носит непротивоправный характер» ${ }^{3}$.

Речь идет о той сфере жизнедеятельности человека, которая не подлежит контролю со стороны общества и государства. Таким образом, если информация о личности отнесена к сведениям, подлежащим предоставлению, то она не может относится к частной жизни лица (например, фамилия, имя и отчество лица, его семейное положение). Кроме того, эта сфера должна носить непротивоправный характер, то есть не подлежат уголовно-правовой защите сведения о совершенных лицом преступлениях, правонарушениях. Нельзя говорить о семейной тайне, если речь идет о жестоком обращении с детьми в семье как элементе воспитания.

Как уже было отмечено выше, исходя из нормы уголовного закона уголовно-правовой охране подлежат не любые сведения о частной жизни лица, а только те, которые составляют его личную или семейную тайну. К сведениям, составляющим личную тайну, могут относиться любые сведения о лице, касающиеся его интересов, убеждений, взглядов, привычек, взаимоотношений, которые он стремится сохранить в тайне от окружающих, то есть такие сведения, в отношении которых потерпевшим необходимо принять меры, обеспечивающие их конфиденциальность и сохранность от третьих лиц. Обязательным условием отнесения тех или иных сведений к личной тайне является их недоступность третьим лицам. Не может рассматриваться в качестве личной тайны информация, доступ к которой не ограничен. Например, если сведения об имущественном положении или состоянии здоровья размещают на рабочем столе служебного компьютера, доступ к которому имеется у многих сотрудников, то данная информация не может относится к тайне, так как лицо не скрывает ее от окружающих, не ограничивает доступ к ней.

При квалификации по ст.137 УК РФ должно учитываться не только мнение потерпевшего о том, что это его личная тайна, но и субъективная сторона виновного, который должен понимать, что собирает сведения, составляющие тайну личную или семейную. Как указано в Постановление Пленума Верховного Суда РФ от 25 декабря 2018 г. № 46 «О некоторых вопросах судебной практики по

\footnotetext{
${ }^{3}$ Определения Конституционного Суда Российской Федерации от 9 июня 2005 года № 248-О, от 26 января 2010 года № 158-О-О и от 27 мая 2010 года № 644-О-О // СПС «Гарант».
} 
делам о преступлениях против конституционных прав и свобод человека и гражданина (статьи 137 , $138,138.1,139,144.1,145,145.1$ Уголовного кодекса Российской Федерации)», «при решении вопроса о наличии в действиях лица состава преступления, предусмотренного частью 1 или 2 статьи 137 УК РФ, суду необходимо устанавливать, охватывалось ли его умыслом, что сведения о частной жизни гражданина хранятся им в тайне» ${ }^{4}$.

Соответственно, если доступ не ограничен, нет никаких препятствий к ознакомлению с информацией, то и лицо не может осознавать противозаконность своих действий. Кроме того, в постановлении также указывается, что «с учетом положений указанных норм уголовного закона в их взаимосвязи с положениями пункта 1 статьи 152.2 Гражданского кодекса Российской Федерации не может повлечь уголовную ответственность собирание или распространение таких сведений в случаях, если сведения о частной жизни гражданина ранее стали общедоступными либо были преданы огласке самим гражданином или по его воле» 5 .

На сегодняшний день самыми распространенными сведениями, составляющими личную тайну, по материалам судебной практики выступают фотоизображения в обнаженном виде, которые были получены путем неправомерного доступа к компьютерной информации или были переданы самому виновному.

Разграничивая понятия частной жизни лица и личной тайны следует отметить, что, например, сведения о месте жительства, месте работы, учебы будут относится к сфере частной жизни лица, но не будут являться личной или семейной тайной в силу того, что эта информация в принципе не может быть тайной, ее невозможно скрыть от окружающих, обеспечить ее конфиденциальность.

Исходя из вышеизложенного представляется, что для устранения коллизий между конституционными нормами и нормой Уголовного кодекса РФ, а также для расширения сферы уголовноправовой защиты частной жизни лица следует исключить из текста ст. 137 УК РФ указание о личной или семейной тайне и оставить в качестве предмета уголовно-правовой охраны только сведения о частной жизни лица. Подобная формулировка позволит избежать трудностей в оценке таких понятий, как личная тайна и семейная тайна. Таким образом, собирание и распространение любых сведений о частной жизни лица будет образовывать состав преступления. Любое незаконное вмешательство в сферу частной жизни будет рассматриваться как преступление.

Особое внимание следует уделить вопросу о сфере частной жизни лица, касающейся взаимоотношений внутри семьи. Можно ли привлечь к ответственности супруга, который собирает информацию о жене, подозревая ее в неверности, или родителей, собирающих сведения о своих детях? Можем ли мы говорить о личной тайне супругов, детей?

При решении этого вопроса следует выделить несколько аспектов, на которых необходимо остановиться и проанализировать.

Во-первых, безусловно, все лица имеют право на неприкосновенность частной жизни, и каждому гарантируется защита его личной тайны независимо от возраста. Ребенок, как и любое другое лицо, имеет право на личную жизнь, и никто не может вмешиваться в осуществление этого права. Но здесь речь идет о недопустимости нарушения его права со стороны третьих лиц, а что касается его родителей, то здесь мы сталкиваемся с обязанностью родителей заботиться о своих детях, родители несут ответственность за духовное, нравственное, психическое развитие своих детей. Реализуя свои права и обязанности, родители так или иначе должны обладать необходимой информацией об образе жизни своих детей, об их наклонностях, интересах, состоянии здоровья, круге друзей и т. д. Личная жизнь детей должна контролироваться родителями. Это необходимо, прежде всего, для обеспечения безопасности детей от вмешательства в их духовное, нравственное и физическое развитие со стороны других лиц, от незаконного воздействия на их психическое здоровье, от вовлечения их в различные незаконные действия и организации. На сегодняшний день дети большую часть своего свободного времени проводят в Интернете, общаясь на различных ресурсах и платформах с лицами, не известными родителям и друзьям. Очень сложно контролировать круг общения детей, их интересы и увле-

\footnotetext{
${ }^{4}$ Постановление Пленума Верховного Суда РФ от 25 декабря 2018 г. № 46 «О некоторых вопросах судебной практики по делам о преступлениях против конституционных прав и свобод человека и гражданина (статьи 137 , 138, 138.1, 139, 144.1, 145, 145.1 Уголовного кодекса Российской Федерации)» // СПС «Гарант».

${ }^{5}$ Постановление Пленума Верховного Суда РФ от 25 декабря 2018 г. № 46 «О некоторых вопросах судебной практики по делам о преступлениях против конституционных прав и свобод человека и гражданина (статьи 137 , 138, 138.1, 139, 144.1, 145, 145.1 Уголовного кодекса Российской Федерации)» // СПС «Гарант».
} 
чения, взгляды и убеждения, которые могут формироваться под влиянием криминальных структур и организаций. Дети часто становятся жертвами сексуальных преступлений, подвергаются издевательству и унижению со стороны других лиц в Интернете, вовлекаются в совершение таких преступлений, как незаконный оборот наркотиков, экстремизм и терроризм.

Таким образом, исходя из предполагаемого права и обязанности родителей воспитывать своих детей они должны быть исключены из числа субъектов уголовной ответственности за собирание сведений о их частной жизни. Родители, действующие в интересах своих детей, собирающие информацию о круге их интересов, взглядах, друзьях и деятельности в свободное от учебы время и другую информацию о частной жизни детей, не подлежат уголовной ответственности по ст. 137 УК РФ.

Сложнее обстоит дело с супругами. Представляется, что если одни из супругов собирает сведения, о том, где и с кем проводит время другой из супругов, выясняет круг его общения и интересов, то рассматривать данные действия как преступные мы не можем. Супруги имеют право знать сведения о втором из супругов, но узнав эти сведения, они не могут их распространять третьим лицам. Супруги исключаются из числа лиц, которые могут нести ответственность за собирание этих сведений, но они могут быть привлечены к уголовной ответственности за незаконное распространение данных сведений.

Следует также остановиться на вопросе объективной стороны преступления, предусмотренного ст. 137 УК РФ. В диспозиции статьи указывается на три действия, образующих объективную сторону рассматриваемого преступления: незаконное собирание сведений о частной жизни лица без его согласия, незаконное распространение сведений о частной жизни лица без его согласия и распространение этих сведений в публичном выступлении, публично демонстрирующемся произведении или средствах массовой информации.

Обязательными признаками собирания и распространения этих сведений являются их незаконность и отсутствие согласия потерпевшего. Причем, если собирание осуществляется путем нарушения тайны переписки, телефонных переговоров, сообщений, то необходимо дополнительно квалифицировать по ст.138 УК РФ, предусматривающей ответственность за нарушение тайны переписки, телефонных переговоров, почтовых, телеграфных и иных сообщений 6 .

Обращаясь к вопросу о квалификации действий лица, собирающего сведения о частной жизни путем неправомерного доступа к компьютерной информации, следует отметить, что в данном случае необходимо квалифицировать действия по совокупности преступлений, указанных в ст.137 УК РФ и ст.272 УК РФ, предусматривающих ответственность за неправомерный доступ к компьютерной информации. Здесь можно отметить, что вред причиняется различным отношениям, с одной стороны это отношения, обеспечивающие конституционное право на неприкосновенность частной жизни лица, а с другой - это отношения, обеспечивающие защиту компьютерной информации. Таким же путем идет и судебная практика. В основной массе проанализированных уголовных дел по ст.137 УК РФ в случаях, если собирание сведений осуществлялось путем, например, взлома аккаунтов, подбора логинов и паролей, то в приговорах указывалось на совокупность преступлений.

В литературе неоднократно отмечалась необходимость дифференцированного подхода к уголовной ответственности за незаконное распространение сведений и их публичное распространение. Публичный способ распространения характеризуется большей степенью общественной опасности, когда сведения становятся доступны большому количеству людей, особенно если к ним предоставляется неограниченный доступ в сети Интернет. Целесообразнее данное деяние предусмотреть в числе квалифицирующих признаков в ч. 2 ст. 137 УК РФ.

Нельзя не сказать и о субъективной стороне рассматриваемого состава, которая характеризуется только прямым умыслом. Виновное лицо должно знать, что оно собирает сведения, составляющие личную или семейную тайну. Если информация размещена в открытом доступе или известна многим лицам, то состава преступления не будет. Вызывает сомнения правильность квалификации действий в случаях, если потерпевший сам предоставил информацию о своей личной жизни лицу, которое впоследствии передало эти сведения третьим лицам.

Обращаясь к квалифицированному составу рассматриваемого преступления, можно отметить, что в качестве лица, использующего свое служебное положение, следует рассматривать должностных лиц, государственных и муниципальных служащих, не являющихся должностными лицами и лиц,

\footnotetext{
${ }^{6}$ Уголовный кодекс РФ 1996 г. // СПС «Гарант».
} 
выполняющих управленческие функции в коммерческой или иной организации. Данный вывод основывается на анализе положений постановлений Пленумов Верховного Суда РФ, разъясняющих аналогичные квалифицирующие признаки. В частности, в Постановлении Пленума Верховного Суда РФ от 30 ноября 2017 г. № 48 «О судебной практике по делам о мошенничестве, присвоении и растрате» в п.29. указывается, что «под лицами, использующими свое служебное положение при совершении мошенничества, присвоения или растраты (часть 3 статьи 159, часть 3 статьи 159.1, часть 3 статьи 159.2, часть 3 статьи 159.3, часть 3 статьи 159.5, часть 3 статьи 159.6, часть 3 статьи 160 УК РФ), следует понимать должностных лиц, обладающих признаками, предусмотренными пунктом 1 примечаний к статье 285 УК РФ, государственных или муниципальных служащих, не являющихся должностными лицами, а также иных лиц, отвечающих требованиям, предусмотренным пунктом 1 примечаний к статье 201 УК РФ (например, лицо, которое использует для совершения хищения чужого имущества свои служебные полномочия, включающие организационно-распорядительные или административно-хозяйственные обязанности в коммерческой организации)» 7 . В целях единообразного подхода к основным понятиям, содержащимся в Уголовном кодексе РФ следует данные разъяснения распространить и на преступление, предусмотренное ст. 137 УК РФ.

Часть 3 ст. 137 УК РФ предусматривает ответственность за «незаконное распространение в публичном выступлении, публично демонстрирующемся произведении, средствах массовой информации или информационно-телекоммуникационных сетях информации, указывающей на личность несовершеннолетнего потерпевшего, не достигшего шестнадцатилетнего возраста, по уголовному делу, либо информации, содержащей описание полученных им в связи с преступлением физических или нравственных страданий, повлекшее причинение вреда здоровью несовершеннолетнего, или психическое расстройство несовершеннолетнего, или иные тяжкие последствия» 8 .

В данном случае речь идет о таком объекте уголовно-правой охраны, как отношения, обеспечивающие защиту прав и законных интересов несовершеннолетних, потерпевших от преступлений. Распространение информации о несовершеннолетних потерпевших причиняет вред не столько частной жизни лица, сколько нормальному психическому, нравственному развитию несовершеннолетнего. Такие дети часто подвергаются унижениям и гонениям со стороны сверстников и даже педагогов, что причиняет им существенные страдания и зачастую приводит к печальным последствиям.

Кроме того, сведения о том, что то или иное лицо выступало в качестве потерпевшего по уголовному делу, нельзя однозначно относить к частной жизни лица, составляющей его личную или семейную тайну. Наделение лица статусом потерпевшего является процессуальным действием, влекущим возникновение прав и обязанностей у лица, связанных с осуществлением правосудия. Кроме того, в соответствии со ст.241 УПК РФ разбирательство во всех судах открытое, за рядом исключений, в том числе если «рассматриваются уголовные дела о преступлениях, совершенных лицами, не достигшими возраста шестнадцати лет» ${ }^{9}$. Но связано это не с охраной частной жизни лица, а, прежде всего, с защитой интересов несовершеннолетних.

Таким образом, можно сделать вывод, что непосредственным объектом рассматриваемого преступления выступают не общественные отношения, обеспечивающие неприкосновенность частной жизни лица, а отношения, обеспечивающие защиту прав и интересов несовершеннолетних потерпевших. Исходя из этого целесообразнее ответственность за данные деяние предусмотреть в гл. 20 «Преступления против семьи и несовершеннолетних».

Предметом преступления по ч. 3 ст. 137 УК РФ будут выступать две группы сведений: первая это сведения, указывающие на личность потерпевшего по уголовному делу, не достигшего 16-летнего возраста. К таким сведениям будет относиться любая информация, по которой можно идентифицировать несовершеннолетнего (фамилия, имя, отчество, его фотографии, изображения). Вторая группа сведений - это информация, которая содержит описание полученных несовершеннолетним в связи с совершением в отношении него преступления страданий, как физических, так и нравственных.

Объективная сторона характеризуется рядом признаков. Во-первых, это деяние, которое заключается в распространении информации о несовершеннолетнем потерпевшем или о полученных им страданиях публично. Обязательным признаком выступает публичность, то есть сведения должны распространяться в СМИ, через информационно-телекоммуникационные сети, в публичных выступлениях, произ-

\footnotetext{
${ }^{7}$ Постановлении Пленума Верховного Суда РФ от 30 ноября 2017 г. № 48 «О судебной практике по делам о мошенничестве, присвоении и растрате» // СПС «Гарант».

${ }^{8}$ Уголовный кодекс РФ 1996 г. // СПС «Гарант».

${ }^{9}$ Уголовно-процессуальный кодекс РФ // СПС «Гарант».
} 
ведениях, демонстрирующихся публично. Если информация передается в личной беседе, разговоре, то состава преступления не будет. Распространение будет в тех случаях, когда к этим сведениям предоставляется доступ неограниченного круга лиц, когда информация размещается в социальных сетях.

Обязательным признаком объективной стороны выступают последствия, в качестве которых законодатель указывает вред здоровью несовершеннолетнего или психическое расстройство несовершеннолетнего, или иные тяжкие последствия. Последствие в виде вреда здоровью предполагает причинение легкого вреда здоровью, признаки которого раскрыты в ст. 115 УК РФ и средней тяжести вреда здоровью, признаки которого предусмотрены в ст. 112 УК РФ. Если же последствия выражаются в причинении тяжкого вреда здоровью потерпевшему, то возникает вопрос о дополнительной квалификации по ст. 111 УК РФ, предусматривающей ответственность за умышленное причинение тяжкого вреда здоровью человека.

С одной стороны, санкция ст. 137 УК РФ предусматривает максимальное наказание в виде пяти лет лишения свободы, в санкции же ст. 111 УК РФ максимальное наказание установлено до восьми лет лишения свободы. Таким образом, в случае наступления последствий в виде тяжкого вреда здоровью требуется дополнительная квалификация по ст. 111 УК РФ.

С другой стороны, в числе последствий по рассматриваемому составу законодатель указывает на психическое расстройство, которое наступает у несовершеннолетнего в результате публичного распространения о нем информации. Само по себе психическое расстройство, которое наступает в результате воздействия на организм потерпевшего, в соответствии со ст. 111 УК РФ относится к тяжкому вреду здоровью. Таким образом, один из признаков тяжкого вреда здоровью указывается в качестве самостоятельного признака ч. 3 ст. 137 УК РФ. Представляется, что подобное указание следует рассматривать как еще один довод в пользу аргумента о необходимости квалифицировать по совокупности преступлений, если в результате распространения сведений о потерпевшем несовершеннолетнем был причинен тяжкий вред здоровью. Кроме того, указание на психическое расстройство как одно из последствий данного преступления, наряду с причинением вреда здоровью, представляется излишним. Поэтому предлагаем исключить из диспозиции ч. 3 ст. 137 УК РФ такое последствие, как психическое расстройство.

Еще одно последствие, указанное в диспозиции ч. 3 ст. 137 УК РФ,- иные тяжкие последствия. Данный признак достаточно часто встречается в Уголовном кодексе РФ и носит оценочный характер. Верховный Суд РФ в своем Постановлении Пленума от 04.12.2014 № 16 «О судебной практике по делам о преступлениях против половой неприкосновенности и половой свободы личности» к иным тяжким последствиям, которые могут наступить в результате изнасилования, отнес «самоубийство или попытку самоубийства потерпевшего лица» ${ }^{10}$. Думается, что вполне уместно распространить данное разъяснение и на рассматриваемое преступление. Как уже было отмечено выше, очень часто жертвы преступлений, особенно несовершеннолетние, подвергаются гонениям и унижениям со стороны сверстников, соседей, что причиняет нравственные страдания и может привести к самоубийству лица.

Проблематичным остается вопрос причинно-следственной связи рассматриваемого преступления. Очень сложно установить связь между публичным распространением сведений о несовершеннолетнем потерпевшем и последствиями в виде вреда здоровью, психического расстройства. Здесь речь идет о том, что в результате распространения сведений о несовершеннолетнем потерпевшем или понесенных им физических или психических страданиях был причинен вред здоровью или наступило психическое расстройство, тем более что психическое расстройство может наступить и в результате того преступления, которое было совершено в отношении жертвы. Этим скорее всего и объясняется отсутствие судебной практики по ч. 3 ст. 137 УК РФ. За последние пять лет нет ни одного случая привлечения к уголовной ответственности за «незаконное распространение в публичном выступлении, публично демонстрирующемся произведении, средствах массовой информации или информационно-телекоммуникационных сетях информации, указывающей на личность несовершеннолетнего потерпевшего, не достигшего шестнадцатилетнего возраста, по уголовному делу, либо информации, содержащей описание полученных им в связи с преступлением физических или нравственных страданий, повлекшее причинение вреда здоровью несовершеннолетнего, или психическое расстройство несовершеннолетнего, или иные тяжкие последствия».

\footnotetext{
${ }^{10}$ Постановлении Пленума Верховного Суда от 04.12.2014 №16 «О судебной практике по делам о преступлениях против половой неприкосновенности и половой свободы личности» // СПС «Гарант».

${ }^{11}$ Уголовный кодекс РФ // СПС «Гарант».
} 
Не менее сложным является и вопрос определения субъективной стороны данного преступления. В диспозиции статьи не указывается на форму вины. В связи с чем напрашивается вывод, что в данном случае преступление может быть совершено как умышленно, так и по неосторожности. Но возможность умышленной формы вины в данном случае вызывает сомнения. Рассматриваемое преступление относится к категории средней тяжести, что касается умышленного причинения тяжкого вреда здоровью и доведения до самоубийства, то они относятся к категории тяжких и особо тяжких (если доведение до самоубийства осуществляется в отношении несовершеннолетнего). Таким образом, можно сделать вывод, что диспозицией ч. 3 ст. 137 УК РФ охватывается умышленное причинение легкого и средней тяжести вреда здоровью, наступивших в результате публичного распространения сведений о потерпевшем несовершеннолетнем, а также наступления последствий в виде тяжкого вреда здоровью или самоубийства несовершеннолетнего по неосторожности. В случае если умыслом лица охватывались последствия в виде тяжкого вреда здоровью или самоубийства жертвы, то требуется дополнительная квалификация по ст. 111 УК РФ и п. «а» ч. 2 ст. 110 УК РФ.

В заключение следует отметить, что с учетом динамично изменяющихся общественных отношений в сторону развития и массового внедрения информационно-телекоммуникационных сетей, перехода общества на новый коммуникативный уровень следует пересмотреть и скорректировать уголовно-правовые нормы, направленные на охрану информации о частной жизни лица. Но не стоит забывать и о том, что необходимо повышать информационную грамотность населения в части защиты той информации, которую они хотят сохранить в тайне. На основе анализа материалов судебной практики по вопросам применения ст. 137 УК РФ можно сделать вывод, что по многим из них возникают сомнения в правильности уголовно-правовой оценки содеянного, так как сами потерпевшие не предпринимали никаких мер, чтобы сохранить информацию в тайне (пересылали их виновным лицам, размещали на рабочих столах служебных компьютеров и т. д.).

Поступила в редакцию 22.05.2019

Стяжкина Светлана Александровна, кандидат юридических наук, доцент кафедры уголовного права и криминологии ИПСУБ УдГУ

ФГБОУ ВО «Удмуртский государственный университет»

426034, Россия, г. Ижевск, ул. Университетская, 1 (корп. 4)

\section{S.A. Styazhkina}

\section{CRIMINAL AND LEGAL PROTECTION OF PRIVATE LIFE}

DOI: $10.35634 / 2412-9593-2019-29-4-538-544$

The article deals with the issues of qualifying a crime under Article 137 of the Criminal Code of the Russian Federation "Violation of the privacy of a person." Particular attention is paid to the problem of defining the concepts of "private life of a person", "personal secret", "family secret" as subjects of criminal law protection. The objective and subjective signs of the composition of the violation of the privacy of persons are analyzed, as well as the issues of excluding individuals from the list of subjects for a given offense. The author proposes to make changes to Article 137 of the Criminal Code of the Russian Federation concerning the subject of the crime and the classification of a number of signs of the objective side as qualified. Signs of a crime under part 3 of Article 137 of the Criminal Code of the Russian Federation are analyzed in sufficient detail: responsibility for illegal dissemination in a public speech, publicly demonstrated work, media or information and telecommunication networks of information indicating the identity of a minor victim who has not reached the age of sixteen years old in a criminal case or information containing a description of physical or moral suffering received by him in connection with a crime, entailing harm to the health of a minor, or a mental disorder of a minor, or other serious consequences.

Keywords: private life of a person, personal secret, family secret, dissemination of information, collection of information, publicity.

Styazhkina S.A., Candidate of Law, Associate Professor

Udmurt State University

Universitetskaya st., 1/4, Izhevsk, Russia, 426034 